\title{
Shuttle box avoidance learning and epinephrine ${ }^{1}$
}

C. N. STEWART AND K. H. BROOKSHIRE FRANKLIN AND MARSHALL COLLEGE

Rats were trained on a two way shuttle avoidance response under one of two doses of epinephrine or placebo conditions. No effect of the hormone was found in female rats, while males learned less effectively under high doses of the hormone. No facilitation of avoidance learning was found at either dosage.

The involvement of epinephrine in fear mediated types of instrumental behavior such as avoidance conditioning, while theoretically attractive, had no experimental foundation until the report of Latane \& Schachter (1962) that a low dose of this hormone facilitated the acquisition of a conditioned avoidance response (CAR) in rats. Previous investigations had found either no effect of the hormone (Moyer \& Bunnell, 1958) or a decrement in CAR frequency (Sines, 1959; Kosman \& Gerard, 1955), although the latter study was concerned with performance and not acquisition of a CAR. It was suggested by Latane \& Schachter (1962) that the failure to obtain epinephrine effects in studies involving fear was a function of the dosages used, and that the relationship between epinephrine concentration and CAR learning took the form of a nonmonotonic inverted $U$. Thus, up to a point low dosages would facilitate avoidance learning, but beyond a certain point the effects would be negative. possibly because of physiological debilitation.

Since the involvement of epinephrine in CAR learning is of some relevance to fear mediation explanations of this behavior, it was thought worthwhile to attempt to replicate the finding of Latane \& Schachter (1962) and to include both male and female Ss in the study. since their investigation included only males.

Wethed

Male and female Sprague-Dawley rats (Holtzman) of age 90-120 days, maintained on an ad lib feeding schedule, were used as Ss. Twenty Ss (10 male, 10 female) were assigned to each of three treatment conditions: placebo (0.5 cc peanut oil); $0.125 \mathrm{mg} /$ $100 \mathrm{~g}$ body weight epinephrine (.0001 solution); or $0.50 \mathrm{mg} / 100 \mathrm{~g}$ body weight epinephrine (.004 solution). The epinephrine was in a peanut oll suspension, and all injections were given subcutaneously in the nape of the neck.

The apparatus consisted of a two compartment shuttle box painted flat gray except for the grid floor and a Plexiglas front wall. The grid floor (1/8 in. brass rods, $3 / 8$ in. apart) was electrified through an Applegate constant current stimulator (Model 250) fed through a Lehigh Valley (Model 1331S) shock scanner. Raising the Masonite door between compartments released a microswitch which turned on a $15 \mathrm{~W}$ bulb (CS) in the compartment the $S$ was to leave, and activated a Hunter decade interval timer which controlled the onset of the US (1.5 mA peak intensity). Response latency (crossing to the other compartment) was recorded by means of a photocell placed across the guillotine door between compartments.

Following injection, Ss were placed in a restraining cage with access to food and water for $45 \mathrm{~min}$ and then transferred to the shuttle box for a $10 \mathrm{~min}$ period of observation. During this period the door between compartments was open and a record was kept of the number of spontaneous crossings. At the end of this $10 \mathrm{~min}$ period the avoidance conditioning trials were begun. The CS-US and intertrial intervals were 5.0 and $30.0 \mathrm{sec}$, respectively, with each $S$ being tested for 200 trials. If $S$ crossed prior to US onset (CAR), the CS was terminated when the crossing was made. Similarly when $S$ crossed after US onset, both CS and US were terminated when the crossing was made. Results and Discussion

Table 1 presents, for each group of Ss, data on various performance measures taken in the shuttle box.

On each of these measures except mean escape time, the data for males and females were analyzed separately by means of a Kruskal-Wallis one way analysis of variance, corrected for ties. For total number of pretrial crossings the three groups of males did not differ significantly $(H=5.91, d f=2, p)$ $.05)$, whereas the females did $(H=13.62$, df $=2, p<$ .05). This difference was in the direction of a decrease in spontaneous activity with increasing epinephrine dosage.

The mean escape time on the first five escape trials was analyzed by means of a 2 by 3 (sex by epinephrine)

Table 1. Epinephrine effects upon avoidance behavior

\begin{tabular}{|c|c|c|c|c|c|c|}
\hline Condition & Sex & $\mathbf{N}$ & $\begin{array}{l}\text { Mean No. } \\
\text { Precross- } \\
\text { ings }\end{array}$ & $\begin{array}{l}\text { Mean } \\
\text { Escape } \\
\text { Time } \\
\end{array}$ & $\begin{array}{l}\text { Mean } \\
\text { Total } \\
\text { CARs }\end{array}$ & $\begin{array}{l}\text { Median } \\
\text { Trials to } \\
\text { Criterion }\end{array}$ \\
\hline Placebo & $\begin{array}{l}\text { M } \\
\mathbf{F}\end{array}$ & $\begin{array}{l}10 \\
10\end{array}$ & $\begin{array}{r}7.90 \\
14.70\end{array}$ & $\begin{array}{l}9.13 \\
7.38\end{array}$ & $\begin{array}{r}103.3 \\
70.0\end{array}$ & $\begin{array}{r}71.5 \\
171.5\end{array}$ \\
\hline $\begin{array}{l}.0125 \mathrm{mg} / 100 \mathrm{~g} \\
\text { epinephrine }\end{array}$ & $\begin{array}{l}\mathrm{M} \\
\mathrm{F}\end{array}$ & $\begin{array}{l}10 \\
10\end{array}$ & $\begin{array}{l}10.90 \\
10.90\end{array}$ & $\begin{array}{r}10.36 \\
7.70\end{array}$ & $\begin{array}{l}72.2 \\
83.7\end{array}$ & $\begin{array}{r}133 \\
88\end{array}$ \\
\hline $\begin{array}{l}.500 \mathrm{mg} / 100 \mathrm{~g} \\
\text { epinephrine }\end{array}$ & $\begin{array}{l}\mathbf{M} \\
\mathbf{F} \\
\end{array}$ & $\begin{array}{l}10 \\
10 \\
\end{array}$ & $\begin{array}{l}3.30 \\
5.30 \\
\end{array}$ & $\begin{array}{l}9.35 \\
9.46 \\
\end{array}$ & $\begin{array}{l}37.8 \\
63.7 \\
\end{array}$ & $\begin{array}{l}193 \\
135.5 \\
\end{array}$ \\
\hline
\end{tabular}




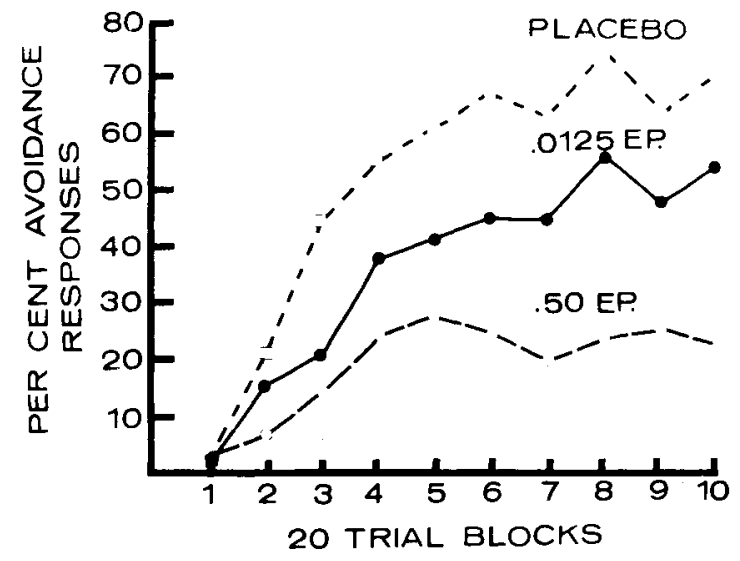

Fig. 1. Mean percentage avoidance responses of male $\mathrm{Ss}$ given two doses of epinephrine or a placebo as a function of trials.

analysis of variance. Neither of the main effects (Drug-F $=.468, \mathrm{df}=2 / 60 ;$ Sex $-F=2.11, \mathrm{df}=1 / 60$ ) nor the interaction $(F=.683, \mathrm{df}=2 / 60)$ was significant.

Analysis of the mean total number of avoidances was found to be significant for male $\mathrm{Ss}(\mathrm{H}=7.57$, df $=2, \mathrm{p}<.05)$ but not for females $(\mathrm{H}=1.78, \mathrm{df}=2, \mathrm{p}>.05)$. The differences between low epinephrine and placebo groups, and between the low and high epinephrine groups, were not significant (White's rank test, $p>.05$ ) whereas the difference between high epinephrine and placebo groups was reliable (White's rank test, $\mathrm{p}<$ .01 ), with the placebo group showing superior avoidance learning.

The total number of trials required to reach a criterion of five consecutive CARs discriminated between males $(H=7.23, \mathrm{df}=2, \mathrm{p}<.05)$ but not females $(\mathrm{H}=1.48$, $\mathrm{df}=2, \mathrm{p}>.05)$. Those Ss who failed to reach the criterion were assigned a score of 200. For males the differences between low epinephrine and placebo, and between low epinephrine and high epinephrine, were not significant (White's rank test, $p>.05$ ). The difference between placebo and high epinephrine was significant (White's rank test, $\mathrm{p}<.05$ ).

Figure 1 shows the mean percent avoidance responses as a function of blocks of 20 trials in the shuttle box for the 30 male rats run in this study. Data on females are not plotted, since they showed no significant hormone effect on this measure. Inspection of these curves in comparison with those published by Latane \& Schachter (1962) reveals a curious paradox: The placebo group in this study performed at a level comparable to the weak (.0125 $\mathrm{mg} / 100 \mathrm{~g}$ ) epinephrine group in their study, and the weak dosage $(.0125 \mathrm{mg} / 100 \mathrm{~g}) \mathrm{Ss}$ in this study performed at a level roughly comparable to their combined $(.25$ and $.50 \mathrm{mg} / 100 \mathrm{~g})$ strong epinephrine groups. The $.50 \mathrm{mg} / 100 \mathrm{~g} \mathrm{Ss}$ in this study showed the poorest learning and had a terminal level of performance below that of the placebo Ss in the Latane and Schachter study. Their poorest performing group was the one given placebo.

The failure of this experiment to replicate the facilitation of avoidance learning found by Latane \& Schachter (1962) under low (.0125 mg/100 g) doses of epinephrine is difficult to interpret. In particular, the lack of comparability of the control groups impairs comparisons between the two studies. Strain of rat, apparatus, shock level, intertrial and CS-US intervals were identical in the two experiments.

It is apparent that sex differences in response to the hormone do exist, with males showing inferior avoidance learning and females no effect at either low or high dosages.

The results are in accord with the hypothesis that high doses of this hormone have a debilitating effect upon rats. This has been found by Kosman \& Gerard (1955) in performance of a CAR, by Leshner \& Stewart (1966) in CAR extinction, and by Sines (1959) in CAR acquisition.

Although the data provide no evidence for a facilitatory effect of epinephrine on the acquisition of conditioned fear, it is possible that the use of the CAR as a dependent variable precludes the detection of this effect. If epinephrine causes motor impairment, then any augmentation of fear would be masked in a situation where a locomotor response is used to measure the strength of conditioned fear.

\section{References}

KOSMAN, M. E., \& GERARD, R. W. The effect of adrenaline on a conditioned avoidance response. J. comp. physiol. Psychol, $1955,48,506-508$.

LATANE, B., \& SCHACHTER, S. Adrenalin and avoidance learning. J. comp. physiol Psychol, 1962, 55, 369-372.

LESHNER, A. I., \& STEWART, C. N. The effect of epinephrine on extinction of an avoidance response. Psychon. Sci, 1966, 5, 89-90. MOYER, K. E., \& BUNNELL, B. N. Effect of injected adrenaline on an avoidance response in the rat. J. genet. Psychol, 1958, 92, 247-251.

SINES, J. O. Reserpine, adrenalin, and avoidance learning in the rat. Psychol Rep., 1959, 5, 321-324.

Note

1. This research was supported by Grants MH 10747 and MH 05874 from the National Institute of Mental Health, U. S. Public Health Service. 